\title{
Editorial: Social Responsibility-Measures and Measurement Viewpoint
}

\author{
Matjaz Mulej • Anita Hrast $\cdot$ Zdenka Zenko
}

Published online: 19 October 2013

(C) Springer Science+Business Media New York 2013

Measurement provides information as a basis for requisitely holistically chosen measures. But: how can one measure the level of holism as the central concept of systemic behavior? How can one measure the level of the requisite holism and the level of interdependence among attributes of the feature under consideration, of the collection of inter-related viewpoints of consideration of it? A new chance is offered by the new international documents on social responsibility (SR; ISO 26000, etc.); ISO 26000 cites interdependence and holism as the common denominators of consideration of any of the seven topics, seven principles, and seven steps of procedure of introduction of SR as an instrument of promotion of systemic behavior.

The collected articles address very different practices and actions. Conclusion from all of them may read: ways of attainment of systemic behavior by SR are very many and very diverse, and so is the measurement, once one does not oversimplify.

This collection of articles by authors from Austria, Croatia, Romania, Russia, Slovenia and USA presents a case of the 'requisite holism' of action that is aimed at insight into systemic behavior via SR from the shared viewpoint of measures and measurement; it is based on the dialectical system approach (Mulej 1974; Mulej and Kajzer 1998): see Table 1.

Reductionism, which Flood criticizes so clearly (2010: 269), causes the fictitious holism/realism: its users reduce their view to single viewpoints in isolation. Bertalanffy (1968: vii) criticized this: he created the General Systems Theory against over-specialization. Mulej (1974 and later, incl. 2013) made a next step with his notion of the dialectical system'. The latter admits that one single viewpoint is not enough for humans to understand and control society, nature, health, education etc. successfully; the ideal and real, i.e., total holism-by linguistic definition-includes totally all viewpoints, relations and

M. Mulej · A. Hrast $\cdot$ Z. Zenko $(\bowtie)$

Faculty of Economics and Business, IRDO Institute for Development of Social Responsibility, University of Maribor, Maribor, Slovenia

e-mail: zdenka.zenko@uni-mb.si

M. Mulej

e-mail: mulej@uni-mb.si 
Table 1 The selected level of holism and realism in consideration of the selected topics between fictitious, requisite, and total holism and realism

\begin{tabular}{ccc}
$\begin{array}{c}\text { Fictitious holism/realism } \\
\text { (inside a single viewpoint) }\end{array}$ & $\begin{array}{c}\text { Requisite holism/realism (a dialectical } \\
\text { system of all essential viewpoints) }\end{array}$ & $\begin{array}{c}\text { Total = real holism/realism (a } \\
\text { system of all viewpoints) }\end{array}$ \\
\hline
\end{tabular}

synergies of attributes; it reaches beyond human capacity, even in team-work that uses interdisciplinary creative cooperation. The dialectical system covers 'knowing of the unknowable', 'managing with the unmanageable', 'learning with the unknowable', and existence of 'mystery and mastery' (Flood 1999); it requires all and only essential viewpoints to be put in interdependence. Mulej (1974) also requires the notion 'system' to be exclusively a 'mental and/or emotional picture of reality', i.e., reality's interpretation from authors' selected viewpoint. Its authors take responsibility for their selection of viewpoints resulting in either hiding or exposing parts of attributes of the object under consideration. In other words: one over-simplifies, if one says that a system exists in real life rather than as mental picture. Several ten 'systems' can describe the same house, field, or person: every traditional science introduces one of these 'systems'. Simplifications are both unavoidable and dangerous: they allow for insights and oversights. The dialectical system tries to help humans solve oversights, if one chooses requisitely holistically the viewpoints, their relations and resulting synergies. Thus, Mulej's dialectical systems theory is a soft one.

The soft systems theories differ from the hard systems by including the ones, which presuppose that the output depends on the input probabilistically rather than deterministically (Checkland 1981). Checkland expressed the difference also by denoting the topic of the soft-system approach as action and action research (rather than discovering natural facts or designing tools on their basis). Human action differs from processes that do not run on conscious self-organization or organization, but on laws, which reflect/are natural facts and are studied from the viewpoints in which single natural and engineering sciences are specialized.

In this selection/collection of articles the object under action research is application of the modern SR concept in ISO 26000 standard (ISO 2010) in the real life: it introduces systemic behavior (including thinking) in the daily practice of the global effort against the socio-economic crisis (EU 2011) by the two central notions, which are essential in the systems theory:

(1) Interdependence and
(2) The holistic approach

Interdependence is the backbone of interrelations and interactions and more: people with ethics of interdependence (i.e., dialectics in ancient Greek language) know and respect their mutual need for, and support from, each other, which helps them to be more holistic rather than one-sided. Ethics of interdependence directs their usage of knowledge and other resources toward more long-term and mutual benefit, while ethics of (e.g., bosses') independence (and their co-workers', nature's, etc.) dependence causes lowquality work, strikes, rebelling, natural disasters, etc., which are very costly. Requisite holism, e.g., via social responsibility, is beneficial rather than costly (as many neo-liberals claim).

This fact is important: reductionism reflects one-sidedness and causes oversights leading to crises, including wars, including world-wars. In the current practice this means that the way out of the current socio-economic crisis is either social responsibility or a new 
world-war. This actual situation is the action under systemic research in this collection of articles. The selected viewpoint is measures and measurement as the informative basis for action.

SR, thus, offers a great variety of supports to the (informal and hence quite acceptable) systemic approach and action; this is demonstrated from the rarely discussed aspect of measurement, here. There are in reality too many topics and aspects within them for one single way of measurement to be enough and cover all of them. This fact opens the arena for further investigation and further attempts to attain the requisite holism instead of onesidedness and its related problems that prevail now, including the current world-wide socio-economic crisis. SR offers a crucial support to solving this crisis. At the same time, SR lies in an invention-innovation-diffusion process, but this viewpoint is outside the scope here (There is more about it in: Mulej et al. 2013).

\section{References}

Checkland P (1981) Systems thinking, systems practice. Wiley, Chichester

EU (2011) Communication from The Commission to The European Parliament, The Council, The European Economic and Social Committee and The Committee of the Regions: a Renewed EU Strategy 2011-2014 for Corporate Social Responsibility. European Commission.Com (2011) 681 Final. Brussels, 25.10.2011

Flood RL (1999) Rethinking the fifth discipline: learning with the unknowable. Routledge, London

Flood RL (2010) The Relationship of 'systems thinking' to action research. Syst Pract Action Res 23:269-284

ISO, International Standards Organization (2010) ISO 26000:2010 ISO [on line], [cited 10 May 2011]. http://www.iso.org/iso/social_responsibility/

Mulej M (1974) Dialekticna teorija sistemov (in Slovene). Nase gospodarstvo 21(3-4):207-212

Mulej M, Kajzer S (1998): Ethics of interdependence and the law of requisite holism. In: Rebernik M, Mulej M (eds) STIQE'98. Proceedings of the 4th international conference on linking systems thinking, innovation, quality, entrepreneurship and environment. University of Maribor, Faculty of Economics and Business, Institute for Entrepreneurship and Small Business Management, and Slovenian Society for Systems Research, Maribor

Mulej M, Bozicnik S, Cancer V et al (2013) Dialectical systems thinking and the law of requisite holism concerning innovation. In: Exploring unity through diversity, vol 3. Emergent Publications, Litchfield Park, AZ

von Bertalanffy L (1968, edition 1979) General systems theory. Foundations, development, applications. Revised Edition. Sixth printing. Braziller, New York 